\title{
Etnosentrik Düzeyine Göre Farklı Ülke Menşeli Ürünlerin Algısı: Kırgız Öğrenciler Örneği *
}

\author{
The perceptions of different country of origin products according to \\ ethnocentric level: The case of Kyrgyz students
}

\section{Emin YÜREKLI 1 a}

\section{Selçuk Burak HAŞILOĞLU ${ }^{2}$}

\footnotetext{
${ }^{1}$ Kırgızistan-Türkiye Manas Üniversitesi, İktisadi ve İdari Bilimler Fakültesi, Bişkek. eyurekli@pau.edu.tr ${ }^{2}$ Pamukkale Üniversitesi, İktisadi ve İdari Bilimler Fakültesi, Denizli. selcukburak@hasiloglu.com a Yazışılan yazar/Corresponding author
}

\section{Özet}

Tüketiciler satın alma karar sürecinde psikolojik, kişilik, sosyal gibi birçok faktörlerden etkilenmektedir. Tüketicinin etnik merkezcilik düzeyleri de bu faktörlerden biridir. Etnosentrizm olarak adlandırilan bu faktör, kişinin kendi din, kültür ve milliyeti odaklı davranması ve bu davranışını satınalma kararına yansıtmasıdır. Bu çalışmanın amacı, Kırgız tüketicilerin etnosentrik düzeylerine göre farklı menşe ülke ürünleri algılarının dağılımın tespit etmektir. Bu amaçla Kırgızistan Manas Üniversitesi ögrrencilerinden veri toplanmış ve örnekleme yöntemi olarak kolayda örnekleme yöntemi kullanılmıştır. Araştırmada CETSCALE ölçeği kullanılarak cevaplayıcıların 5 farklı menşe ülke ürünleri hakkında algılarına yönelik veriler temin edinilmiştir. Daha sonra toplanan bu veriler analize tabii tutularak bulgular ayruntılı bir şekilde yorumlanmıştır. Araştırmada entnosentrik düzeyi arttıkça farklı menşe ülke ürünlere olan pozitif algının da düştüğ̈̈ sonucuna ulaşılmıştır. Yine, cevaplayıcıların Türkiye menşeli ürünler üzerinde pozitif algısının yüksek oldu ŭu tespit edilmiştir. Ancak bu sonucun örnekleme çerçevesinden kaynaklandiğ düşünülmektedir. Zorunluluklardan dolayı oluşturulan örnekleme çerçevesi, araştırmanın en önemli kısıtı olarak kabul edilmiştir. Gelecekte araştırmacuların farklı örnekleme çerçevesi kullanarak bulguları test etmeleri önerilir.

Anahtar kelimeler: Etnosentrizm, Menşe ülke, Tüketici algisı

JEL kodlar: M30, M40, M41.

\begin{abstract}
Consumers is getting effected factors such as psychological, personality, and social. The ethnocentrism of consumer is one of those factors. This factor is that the person is focused on his / her own religion, culture and nationality. In addition, this behaviour of the person is reflected in the decision to purchase. The aim of this study is to determine the distribution of perceptions of different country of origin products according to ethnocentric levels of Kyrgyz consumers. On this purpose, data were collected from the students of Kyrgyzstan Manas University. The convenience sampling method was used as sampling method. Data were collected using the CETSCALE scale for the respondents' perceptions about the products of 5 different countries of origin. Then, these collected data were analysed and interpreted. In this study, it was established that the perceptions of different country of origin products decreased as the ethnocentric level increased. In addition, it was found that respondents were highly positive perception of the Turkish products. However, this result is thought to be caused by the sampling frame. The sampling frame which was formed due to necessities was accepted as the most important limitation of the study. In the future, researchers are advised to test the findings using a different sampling frame.
\end{abstract}

Keywords: Ethnocentrism, Countries of origin, Consumer perception

JEL codes: M30, M40, M41.

\footnotetext{
* Bu makale yazarların, 10-12 Mayıs 2018 tarihlerinde Kırgızistan, Bişkek'te düzenlenen 9. Uluslararası Girişimcilik Kongresi'nde sundukları “Farklı Ülke Menşeili Tekstil Ürünlerinin KTMÜ Öğrenciler Üzerindeki Algısı” başlıklı bildirinin revize edilmiş halidir.
} 


\section{GİRIŞ}

Globalleşen dünya ile birlikte hemen hemen her çeşit tüketim ürününün diş ticareti yoğunlaşmış durumdadır. Bu yoğunlaşma beraberinde tüketiciye ürün çeşitliliği sunmuştur. Ülkeler arası diş ticaret o kadar yoğunlaşmıştır ki beraberinde çokuluslu ve uluslararası işletmeler ortaya çıkmıştır. Bu işletmeler sayesinde bir ürüne ait markanın doğduğu ülke farklı, yönetildiği ülke farklı, üretimin yapıldığı ülke farklı ve hatta o ürünün pazarının bulundu ülke farklı olabilmektedir. Dolayısıyla artık tüketiciler bir ürünü satın alırken farklı menşe ülke çeşitleri ile karşı karşıya kalabilmektedir. İşte bu çeşitlilik tüketici satın alma karar sürecini etkileyen faktörler içerisine menşe ülke etkisi olarak yerini almıştır.

Ürünler üzerinde, "Made in ..." şeklinde bulunan menşe ülke etiketinin kökeni, Birinci Dünya Savaşı'ndan sonraki döneme kadar uzanmaktadır. Başta İngiltere olmak üzere galip ülkeler, Almanya ile doğrudan diş ticareti kesmemiş ancak zorluk çıkartmak amacıyla bu ülkeden ithal edilen ürünler üzerinde menşe ülke etiketinin bulunmasını zorunlu kılmıştır. Böylelikle tüketiciler hangi ürünlerin Alman malı olduğunu bilebilecek ve boykot edebileceklerdi. Ancak kısa bir süre sonra, Alman sanayisi o kadar kaliteli ürünler piyasaya sunmaya başladıki galip ülkelerin tüketicileri boykotun aksine "Made in Germany" etiketini arar olmuştur. (Hasiloglu, 2012).

Bugüne geldiğimizde, tüketicilerin satın alma kararlarında, ürünün üretildiği ülke ve hatta kullanılan hammaddenin geldiği ülke etkili bir faktör olabilmektedir. Bu faktör bir kesim tüketicilerin satın alma karar sürecinde hiç önemli değilken bir başka kesim için öncelikli düzeydedir. Menşe ülke bilgisinin satın alma kararı üzerindeki etkisinde düzenleyicilik görevi gören temel olarak iki faktör bulunmaktadır.

Bunlardan ilki tüketicinin yaşadığ faktördür. Örneğin Suudi Arabistan'da yapılan bir araştırmada ABD, Japonya, Almanya, İtalya, İngiltere ve Fransa menşeli ürünlerin pozitif imaja sahip olduğu bulunmuştur (Bhuian, 1997; Kaynak ve Kara, 2002). Bu faktör özellikle az gelişmiş ile gelişmiş ülkenin birbiri ile kıyaslanmasında önemli rol oynamaktadır (Bilkey ve Nes, 1982). Eğer tüketici az gelişmiş bir ülkede yaşıyorsa gelişmiş bir ülkenin ürünü onun için cazip gelebilmekte ve satın alma kararını olumlu yönde etkileyebilmektedir. Diğer yandan az gelişmiş bir ülkede üretilen bir ürünün menşe ülke algısı olumsuz yönde olabilmektedir. Bu faktör özellikle tüketicinin satın alacağı marka hakkında bilgi sahibi değilse devreye girer. Böyle bir durumda tüketici, ithal ürünün menşe ülkesi hakkında zihninde yer ettiği imajı, o ürüne de transfer eder (Han, 1989). İmaj transferi, üründen ülkeye ya da ülkeden ürüne şeklinde iki yönde de gerçekleşebilir. Örneğin bir tüketici yeni tanıdığı ve menşe ülkesi hakkında bilgi sahibi olmadığı bir markayı çok beğendiyse o markanın menşe ülkesine de olumlu duygular besleyebilir. Diğer yandan bir tüketici satın alacağ hakkında bilgisi var ise ülkeye ait imajını ürüne de transfer edebilir. (Hasiloglu, 2012).

Özden ve Maksüdünov (2012) tarafından yapılan çalışmada, Kırgızistan'da ithal edilen dayanıklı tüketim mallarına karşı tüketici tutum ve davranışlarının belirleyici faktörü olarak menşe ülkesinin önemi araştırılmıştır. 384 katılımcı ile yüz yüze yapılan anket ile elde edilen verilerin analizi sonucunda, menşe ülkesinin satın alma üzerinde önemli bir etkisi olduğu görülmüş ve bu sonuçların, ihracatçı ülkeler ve onların işletmeleri için faydalı olabileceği ifade edilmiştir. 
Menşe ülke bilgisinin satın alma kararı üzerindeki etkisinde düzenleyicilik görevi gören faktörlerden ikincisi etnosentrik düzeyidir. Bu faktör, aynı zamanda bu araştırmanın konusunu içermektedir. Tüketici davranışı yaklaşımı açısında etnosenterizm, kişinin kendi ülkesinde yetişen ya da üretilen ürünleri satın alma eğilimde olması ve bu sayede kendi ülke üreticilerini desteklemesini ifade eder. Anlaşılacağı üzere bu faktör tüketicinin etnosentrik düzeyine göre değişmektedir. Tüketicinin etnosentrik düzeyi arttıkça kendi ülke menşe ürünlerine yönelmesi beklenirken, farklı ülke menşe ürünlere olan talebin düşmesi beklenmektedir. Öyleki o ülkenin ürünleri kaliteli olsa dahi satın almama eğilimindedirler. Diğer taraftan etnosentrik düzeyi düşük olan tüketicilerin satın alma karar sürecinde faydacılık yönlerinin daha baskın olması beklenir. Etnosenterizm, kültürden kültüre, ülkeden ülkeye ve hatta bölgeden bölgeye değişebilmektedir (Kaynak ve Kara, 1998; Kavak, Özkan ve Demirsoy, 2004). Yine tüketicinin yaşadığı yöre, eğitim durumu vb demografik faktörlerin dahi etkili olması beklenir. Diğer yandan etnosenterizmin etkisi ürün çeşidine göre de değişim gösterebilmektedir. Örneğin Kavak vd. (2004), Türkiye'de yapmış olduğu araştırmada, tüketicilerin etnosentrik düzeyi arttıkça İsveç otomobiline karşı olumsuz bir tutum sergilediklerini tespit etmişler ve farklı ürünlerde farklı sonuçlar elde edilebileceğinden diğer ürün grupları için ayrı çalışmalar önermişlerdir.

Lo vd. (2017) menşe ülke ve tüketici etnosentrizminin marka imajına ve ürün değerlendirmesine etkisi üzerine yaptığı çalışmada, tüketici algılarının ve belirli bir ürüne yönelik tutumların belirlenmesinde marka imajının etnosentirizmden üstün olduğunu ortaya koymuşlardır. Toksarı ve Senir (2015) ise Niğde Üniversitesi'nde 314 kişi ile yapmış olduğu çalışmada menşe ülke etkisinin satın alma davranışına etkisini araştırmıştır. Araştırmada tüketicilerin giyim, teknoloji ve kişisel bakım ürünlerinin tüketici tercihleri üzerine odaklanan çalışmada tüketicilerin kaliteye göre tercih yaptıkları ifade edilmiştir.

Konu ile ilgili bir diğer çalışma da İngiltere' de yürütülmüştür (Felzensztein ve Dinnie, 2006). $\mathrm{Bu}$ çalışmada tüketicilerin ithal edilen şaraplara yönelik algılarında menşe ülke etkisi araştırılmıştır. Araştırma sonucunda katılımcıların fiyat, menşe ülke ve üzüm çeşidinin tüketiciler için en önemli seçim kriteri olduğunu ve katılımcıların yenidünya şaraplarını tercih ettiği vurgulanımıştır.

Javed (2013) ise Pakistan'da yapmış olduğu çalışmada tüketicilerin satın alma tercihlerinde menşe ülke etkisini incelemiştir. Araştırma orantısal coğrafi örnekleme tekniği ile 4 farklı şehirden 178 kişi ile yapılmıştır. Satın alma tercihlerinde ürün katılımı, ürün bilgisi gibi tüketicinin ürünler hakkında bir görüntüsü de olduğu ortaya konulmuştur. Araştırma soncunda ise Pakistan'ın sadece elektronik ürünler ve kozmetik ürünlerinde değil, kumaş ürünlerinde tercih edildiği sonucuna varılırken, ürün katılımı ve ürün bilgisi, farklı ürün kategorilerindeki ülkeleri seçerken müşteri tercihlerini etkilediği ifade edilmiştir.

Benzer olarak Haque vd. (2015) tarafından ise tüketicilerin yabancı ürünleri satın alma niyetlerini etkileyen faktörler incelenmiştir. Bangladeş'teki iki şehirde toplam 31 alışveriş merkezinde 230 kişiden veri toplanmıştır. Araştırma sonucunda yabancı ürünlerin marka imajı ve kalitesi bu ürünlerin satın alma niyeti üzerinde olumlu etkisi olduğunu ortaya koymuştur. Ancak dindarlık, yabancı ürünlerin satın alma niyeti üzerinde olumsuz bir etki bıraktığı belirtilmiştir. Ayrıca araştırma sonucunda menşe ülke imajının marka imajı üzerinde 
önemli pozitif bir etki oluşturduğu, fakat etnosentirizmin satın alma niyeti ile yabancı ürünlerin kalitesine ilişkin algıları üzerinde olumsuz etki yarattığı ortaya konulmuştur.

\section{ARAŞTIRMANIN AMACI VE YÖNTEMI}

Araştırmanın amacı, Kırgız öğrencilerin tüketici etnosentrik düzeylerine göre, farklı menşe ülke ürünleri algılarının dağılımını tespit etmektir. Araştırma kapsamında cevaplayıcıların kendi ülkelerinin yanında, Türkiye, Çin, Rusya ve Kazakistan menşeli ürünlerine yönelik algıları değerlendirilmiştir. Bu ülkeler, Kırgızistan'ın en çok ithalatta bulunduğu ülkelerdir. 2016 yılı rakamlarına göre Kırgızistan (MIT, 2018); 2,62 Milyar Dolar değerinde Çin'den (\%51), 941 Milyon Dolar değerinde Rusya'dan (\%18), 482 Milyon Dolar değerinde Kazakistan'dan $(\% 9,4)$ ve 244 Milyon Dolar değerinde Türkiye'den $(\% 4,8)$ ithalatta bulunmuştur.

Kırgız halkının Likert ve stapel tipi ölçeklere alışkın olmaması ve anketlere sıcak bakmamasından dolayı, ana kütlenin geniş tutulması mümkün olamamış ve tesadüfi örnekleme yöntemine başvurulamamıştır. Ülkedeki lisans öğrencileri dahi bu tür saha çalışmalarına alışkın değildirler. Yaklaşık 100 öğrenci ile yapılan pilot çalışmada anket formlarının \%80'nin dikkatsizce ya da anlaşılmadan cevaplandığı tespit edilmiş ve tüm veriler iptal edilmiştir. Bunun önüne geçmek için bu makalenin birinci yazarı ve aynı zamanda Kırgızistan Manas Üniversitesi öğretim üyesi, meslektaşları ile birlikte veri toplama sürecine bizzat dahil olmuştur. Bu bağlamda Kırgızistan Manas Üniversitesi öğrencileri, araştırmanın örnekleme çerçevesi olarak belirlenmiştir. Cevaplayıcıların seçiminde, Likert tipi ölçeklerle oluşturulmuş anket formlarına aşına ve geçmişte cevaplayıcı tecrübesi olma şartı aranmıştır. $\mathrm{Bu}$ açıdan, çalışmada yargıya dayalı örnekleme yönteminin kullanıldığı söylenebilir. Saha çalışmasında 88 cevaplayıcıdan eksiksiz veri toplanmıştır. Cevaplayıcıların cinsiyet dağılımı $\% 50-\% 50$ oranindadir.

Araştırmada veri toplama aracı olarak CETSCALE ölçeği ile birlikte cevaplayıcıların 5 farklı menşe ülke ürünleri hakkında algılarına yönelik maddelere yer verilmiştir. CATSCALE ölçeğinde 5'li Likert tipi ölçek, ülke algılarına yönelik faktörlerde ise $-3,-2,-1,0,+1,+2,+3$ şeklinde stapel ölçeği kullanılmıştır. Cevaplayıcıların 5 ülke algılarının ölçümünde çekici, farklı, güzel, kaliteli, orijinal, özel, satın alırım ve uygun fiyat faktörlerine yer verilmiştir. Bu faktörler, Haşıloğlu (2012)'nun İngiltere' de Türkiye menşeli ürünlerin algısı ile ilgili yapmış olduğu çalışmada, kullandığı değişkenlerden yararlanılarak belirlenmiştir.

Güvenirlilik analizi için ölçeklerin iç tutarlılığına bakılmıştır. Bu doğrultuda 17 maddelik CATSCALE ölçeğinin Cronbach's Alfa katsayısı 0,87 ve 5 ülkeye ait algı faktörleri ölçeğinin Cronbach's Alfa katsayısı 0,81 olarak bulunmuştur.

Araştırmanın amacı doğrultusunda genel olarak 4 soruya cevap aranmıştır:

S1. Öğrenciler açısından menşe ülkeler arasında algı farklılığı var mıdır? Dağılım nedir?

S2. Öğrenciler açısından farklı menşe ülke ürünlerine ait algı faktörleri dağılımı nedir?

S3. Alg1 faktörlerine göre birbirlerine benzer ya da uzak ülkeler hangileridir?

S4. Öğrencilerin etnosentrik düzeylerine göre menşe ülke algı dağılımı nedir? 


\section{BULGULAR}

Cevaplayıcıların CATSCALE ölçeğinin 17 maddesine göre etnosentrik ortalamaları Tablo 1'de verilmiştir. Tablodan görüleceği üzere “M3: Kırgız yapımı ürünler satın alın, Kırgızistan’ın çalışmaya devam etmesini sağlayın." maddesi en yüksek, "M5: Yabancı menşeli ürünleri satın almak Kırgızlığa aykırıdır." maddesi ise en düşük ortalamaya sahiptir.

Tablo 1. CATSCALE Ölçeği Maddeleri Ortalamaları

\begin{tabular}{llcc}
\hline $\begin{array}{c}\text { Maddeler } \\
\text { (siralanmiş) }\end{array}$ & $\mathbf{N}$ & $\begin{array}{c}\text { Ortalama* } \\
\overline{\boldsymbol{x}}\end{array}$ & $\begin{array}{c}\text { Standart Sapma } \\
\text { M3 }\end{array}$ \\
\hline M16 & 88 & 3,63 & 0,96 \\
\hline M13 & 88 & 3,24 & 1,10 \\
\hline M2 & 88 & 3,23 & 1,03 \\
\hline M10 & 88 & 3,13 & 1,17 \\
\hline M8 & 88 & 3,06 & 1,02 \\
\hline M4 & 88 & 3,00 & 1,03 \\
\hline M12 & 88 & 2,93 & 0,92 \\
\hline M9 & 88 & 2,89 & 0,94 \\
\hline M15 & 88 & 2,85 & 0,92 \\
\hline M1 & 88 & 2,76 & 1,01 \\
\hline M11 & 88 & 2,60 & 1,02 \\
\hline M6 & 88 & 2,59 & 0,93 \\
\hline M17 & 88 & 2,56 & 1,07 \\
\hline M14 & 88 & 2,50 & 0,96 \\
\hline M7 & 88 & 2,31 & 0,85 \\
\hline M5 & 88 & 2,17 & 0,97 \\
\hline
\end{tabular}

*Ĕ̆gr; $1 \leq \bar{x}<2,33 \Rightarrow$ "Düşük"; 2,33 $\leq \bar{x}<3,66 \Rightarrow$ "Orta"; 3,66 $\bar{x}<5 \Rightarrow$ "Yüksek"

Tablo 2' de menşe ülkeler arasında algı faktörleri ortalamalarının dağılımı ve bu ortalamalar arasında farklılık testine ilişkin veriler yer almaktadır. Tablodan görüleceği üzere Kırgız cevaplayıcılar açısından Türkiye menşeli ürünler en yüksek olumlu algıya sahiptir. Onu sırasıyla Rusya ve Kırgızistan menşeli ürünler takip etmektedir. Çin menşeli ürünlerin pozitif alg1 düzeyi ise en düşüktür $(p<0,001)$. Bu bulgu araştırmanın aynı zamanda birinci sorusunun cevabını vermektedir.

Tablo 2. Ülkelerin Algı Faktörü Ortalamaları ve Farklılıkları

\begin{tabular}{|c|c|c|c|c|c|c|}
\hline & $\mathbf{N}$ & $\begin{array}{c}\text { Ortalama* } \\
\bar{x}\end{array}$ & $\begin{array}{c}\text { S.Sapma } \\
\sigma\end{array}$ & $\begin{array}{c}\text { Standart } \\
\text { Hata }\end{array}$ & F & $\mathbf{p}$ \\
\hline Kırgizistan & 88 & 1,17 & 0,85 & 0,09 & \multirow{5}{*}{51,560} & \multirow{5}{*}{$<0,001$} \\
\hline Türkiye & 88 & 1,80 & 0,78 & 0,08 & & \\
\hline Çin & 88 & 0,03 & 1,07 & 0,11 & & \\
\hline Rusya & 88 & 1,27 & 0,88 & 0,09 & & \\
\hline Kazakistan & 88 & 0,48 & 0,96 & 0,10 & & \\
\hline
\end{tabular}

Araştırmanın ikinci sorusunun cevabın arandığı Tablo 3'de ise $-3 \ldots+3$ aralığındaki stapel ölçeğine göre ülkelere yönelik alg1 faktörlerinin ortalama değerleri yer almaktadır. Cevaplayıcılara göre Kırgızistan ürünlerinin uygun fiyat faktörü en yüksek düzeye sahipken, farklı faktörü en düşük düzeydedir. Diğer taraftan Türkiye menşeli ürünlerin kaliteli faktörü 
en yüksek düzeye sahipken, uygun fiyat faktörü en düşük düzeydedir. Türkiye'nin aksine, Çin menşeli ürünlerin uygun fiyat faktörü en yüksek düzeye sahipken, kaliteli faktörü en düşük düzeydedir. Türkiye'ye benzer olarak, Rusya menşeli ürünlerin kaliteli faktörü en yüksek düzeye sahipken, uygun fiyat faktörü en düşük düzeydedir. Son olarak, Kazakistan menşeli ürünlerin kaliteli faktörü en yüksek düzeye sahipken, satın alma eğilimi faktörü en düşük düzeydedir. Tüm ülkeler arasında kaliteli faktörü açısından en yüksek ortalamaya Türkiye sahiptir. Bu faktör aynı zamanda tüm faktörler arasında da en yüksek değerdedir.

Tablo 3. Ülkelerin Alg1 Faktörleri Dağılımları

\begin{tabular}{|c|c|c|c|c|}
\hline Ülkeler & Faktörler & $\mathbf{N}$ & $\begin{array}{c}\text { Ortalama* }^{*} \\
\bar{x} \\
\end{array}$ & $\begin{array}{c}\text { Standart Sapma } \\
\sigma \\
\end{array}$ \\
\hline \multirow{8}{*}{ 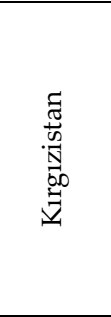 } & Kaliteli & 88 & 1,43 & 1,19 \\
\hline & Uygun fiyat & 88 & 1,76 & 1,16 \\
\hline & Orijinal & 88 & 0,99 & 1,40 \\
\hline & Çekici & 88 & 0,83 & 1,34 \\
\hline & Farklı & 88 & 0,68 & 1,59 \\
\hline & Güzel & 88 & 1,32 & 1,25 \\
\hline & Satın alırım & 88 & 1,40 & 1,11 \\
\hline & Özel & 88 & 0,98 & 1,44 \\
\hline \multirow{8}{*}{ 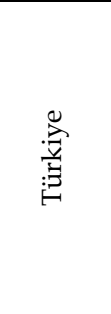 } & Kaliteli & 88 & 2,48 & 0,68 \\
\hline & Uygun fiyat & 88 & 0,57 & 1,75 \\
\hline & Orijinal & 88 & 2,42 & 3,40 \\
\hline & Çekici & 88 & 1,93 & 0,91 \\
\hline & Farklı & 88 & 1,66 & 1,22 \\
\hline & Güzel & 88 & 2,14 & 0,73 \\
\hline & Satın alırım & 88 & 1,73 & 1,12 \\
\hline & Özel & 88 & 1,50 & 1,05 \\
\hline \multirow{8}{*}{ 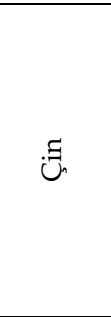 } & Kaliteli & 88 & $-1,19$ & 1,66 \\
\hline & Uygun fiyat & 88 & 1,86 & 1,52 \\
\hline & Orijinal & 88 & $-1,16$ & 1,69 \\
\hline & Çekici & 88 & 0,63 & 1,73 \\
\hline & Farklı & 88 & 0,24 & 1,99 \\
\hline & Güzel & 88 & 0,31 & 1,73 \\
\hline & Satın alırım & 88 & 0,14 & 1,78 \\
\hline & Özel & 88 & $-0,61$ & 1,68 \\
\hline \multirow{8}{*}{ 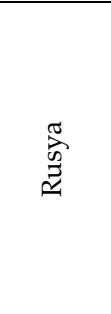 } & Kaliteli & 88 & 2,08 & 0,91 \\
\hline & Uygun fiyat & 88 & 0,80 & 1,58 \\
\hline & Orijinal & 88 & 1,69 & 1,16 \\
\hline & Çekici & 88 & 1,10 & 1,27 \\
\hline & Farklı & 88 & 1,06 & 1,31 \\
\hline & Güzel & 88 & 1,40 & 1,22 \\
\hline & Satın alırım & 88 & 1,09 & 1,36 \\
\hline & Özel & 88 & 0,93 & 1,33 \\
\hline \multirow{8}{*}{ 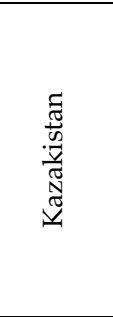 } & Kaliteli & 88 & 0,88 & 1,07 \\
\hline & Uygun fiyat & 88 & 0,67 & 1,40 \\
\hline & Orijinal & 88 & 0,53 & 1,25 \\
\hline & Çekici & 88 & 0,40 & 1,35 \\
\hline & Farklı & 88 & 0,24 & 1,32 \\
\hline & Güzel & 88 & 0,76 & 1,25 \\
\hline & Satın alırım & 88 & 0,17 & 1,62 \\
\hline & Özel & 88 & 0,22 & 1,48 \\
\hline
\end{tabular}

*Ĕger; $-3 \leq \bar{x}<-1 \Rightarrow$ “Düşük"; $-1 \leq \bar{x}<1 \Rightarrow$ “Orta”; $1 \leq \bar{x}<3 \Rightarrow$ "Yüksek"

Ülkelerin birbirlerine benzerliklerine göre Öklid uzaklık değerleri ve uzaklık haritası Grafik 1'de verilmiştir. Bu grafik, aynı zamanda araştırmanın üçüncü sorusunun cevabını 
vermektedir. Çok boyutlu ölçekleme yöntemine göre elde edilen uzaklık haritasından görüleceği üzere Kırgızistan menşeli ürünlerin algı faktörleri değerleri ile Kazakistan menşeli ürünlerin algı faktörleri değerleri birbirine en uzaktır.

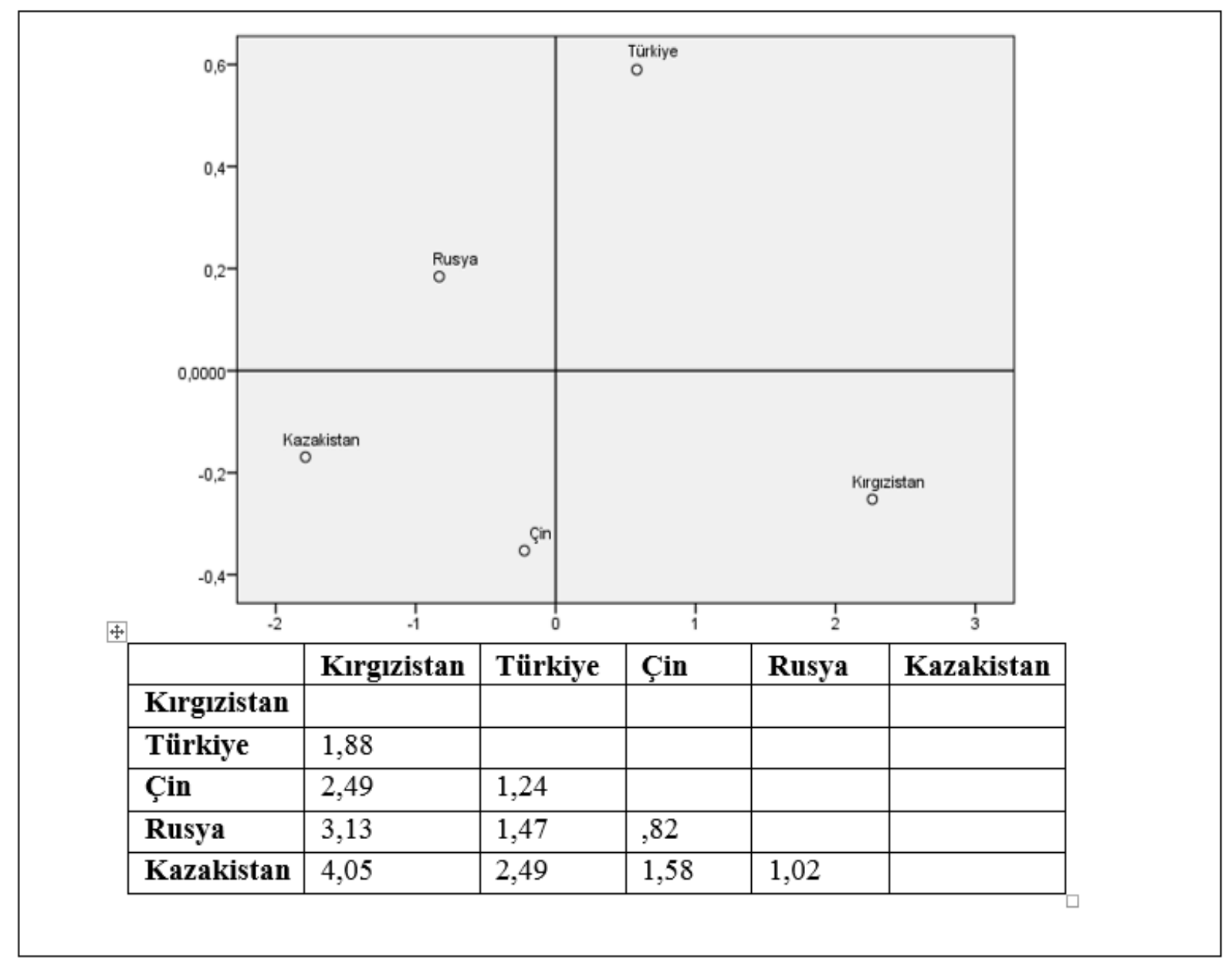

Grafik 1. Algı Faktörleri Değerleri Dağılımına Göre Ülkelerin Uzaklıkları

Tablo 4'te ise cevaplayıcıların etnosentrik düzeylerine göre ülkelerin alg1 faktörü ortalamalarının dağılımı yer almaktadır. Tablodan görüleceği üzere Kırgız cevaplayıcıların etnosentrik düzeyleri artıkça Kırgızistan ürünlerine yönelik algı ortalamaları artarken, diğer ülke ürünlerine yönelik algı ortalamaları azalmaktadır. Tabloda yer alan bulgular araştırmanın aynı zamanda dördüncü sorusunun cevabını vermektedir. 
Tablo 4. Etnosentrik Düzeyine Göre Ülkelerin Algı Faktörü Ortalamaları

\begin{tabular}{|c|c|c|c|c|c|}
\hline & Düzeyler & $\mathbf{N}$ & $\begin{array}{l}\text { Ortalama* } \\
\bar{x}\end{array}$ & $\begin{array}{c}\text { Standart Sapma } \\
\sigma \sigma\end{array}$ & Standart Hata \\
\hline \multirow{4}{*}{ Kırgızistan } & Düşük & 18,00 & 1,20 & 0,74 & 0,18 \\
\hline & Orta & 64,00 & 1,11 & 0,89 & 0,11 \\
\hline & Yüksek & 6,00 & 1,73 & 0,61 & 0,25 \\
\hline & Toplam & 88,00 & 1,17 & 0,85 & 0,09 \\
\hline \multirow{4}{*}{ Türkiye } & Düşük & 18,00 & 1,84 & 0,44 & 0,10 \\
\hline & Orta & 64,00 & 1,82 & 0,85 & 0,11 \\
\hline & Yüksek & 6,00 & 1,54 & 0,80 & 0,33 \\
\hline & Toplam & 88,00 & 1,80 & 0,78 & 0,08 \\
\hline \multirow{4}{*}{ Çin } & Düşük & 18,00 & 0,10 & 1,11 & 0,26 \\
\hline & Orta & 64,00 & 0,04 & 1,07 & 0,13 \\
\hline & Yüksek & 6,00 & $-0,42$ & 0,99 & 0,41 \\
\hline & Toplam & 88,00 & 0,03 & 1,07 & 0,11 \\
\hline \multirow{4}{*}{ Rusya } & Düşük & 18,00 & 1,55 & 0,82 & 0,19 \\
\hline & Orta & 64,00 & 1,21 & 0,92 & 0,11 \\
\hline & Yüksek & 6,00 & 1,08 & 0,55 & 0,22 \\
\hline & Toplam & 88,00 & 1,27 & 0,88 & 0,09 \\
\hline \multirow{4}{*}{ Kazakistan } & Düşük & 18,00 & 0,89 & 0,98 & 0,23 \\
\hline & Orta & 64,00 & 0,43 & 0,91 & 0,11 \\
\hline & Yüksek & 6,00 & $-0,13$ & 1,02 & 0,42 \\
\hline & Toplam & 88,00 & 0,48 & 0,96 & 0,10 \\
\hline
\end{tabular}

*Ĕger; $-3 \leq \bar{x}<-1 \Rightarrow$ "Düşük"; $-1 \leq \bar{x}<1 \Rightarrow$ "Orta"; $1 \leq \bar{x}<3 \Rightarrow$ "Yüksek"

\section{SONUÇ}

Çalışma, Kırgız tüketicilerin etnosentrik düzeylerine göre farklı menşe ülke ürünlerine göre algılarının dağılımının belirlenmek amacı ile gerçekleşmiştir. Bu amaç kapsamında yapılan analizler sonucunda elde edilen bulgular dikkate alındığında:

- Ülkelerin birbirine olan coğrafi uzaklıkları ile tercih edilen ürün menşenin ilgisinin olmadığı, aksine Kırgızistan ve Kazakistan arasında en fazla farkın olduğu tespit edilmiştir.

- Etnosentrik düzeyleri artan Kırgız cevaplayıcıların, Kırgızistan menşeli ürünlere pozitif algılarının arttı̆̆ı ve başta Çin olmak üzere diğer ülkelerin ürünlerinden uzaklaştıkları belirlenmiştir.

- Ürün tercihi dikkate alındığında Türkiye menşeli ürünler cevaplayıcılar açısından en yüksek olumlu algı puanına sahiptir. Türkiye'nin Türki Cumhuriyetler arasındaki konumu, köken ve kültürel yakınlıklarının olmasının bu sonuçta etkisi olduğu söylenebilir.

Tüketicilerin etnosentrik düzeylerinin ürün menşesini dikkate alma ve satın alma tercihlerinde etkili olduğu bu çalışma ile bir kez daha ortaya konmuştur. Bununla birlikte kültürel, etnik yakınlıkların tek başına seçim nedeni olmadığı ve gelişmişlik düzeyinin de 
önemli bir seçim faktörü olduğu çalışma bulgularından okunması gereken önemli sonuçlardır. Çalışmada Kırgız yapımı ürünlere destek verilmesi gerekliliği ile birlikte Kırgız ürünlerini tercih etmemenin de doğal bir sonuç olduğu katılımcılar tarafından ifade edilen önemli sonuçlardandır.

Çalışma kapsamında sadece 88 katılımcıdan alınan verilerin analiz edilmesi, sadece Kırgızistan-Türkiye Manas Üniversitesi öğrencilerinin katılımcı olarak yer alması, Kırgızistan, Türkiye, Çin, Rusya ve Kazakistan menşeli ürünlerin değerlendirilmesinin sorulması araştırma kısıtlılıkları olarak ifade edilebilir.

\section{KAYNAKÇA}

Bhuian, S. N. (1997). Saudi Consumers' Attitudes towards European, US and Japanese Products and Marketing Practices. European Journal of Marketing, 31(7), 467-486.

Bilkey, W.J., \& Nes, E. (1982). Country-Of-Origin Effects on Product Evaluations. Journal of International Business Studies, 13(1), 89-100.

Felzensztein, C., \& Dinnie, K. (2006). The Effects of Country of Origin on UK Consumers' Perceptions of Imported Wines. Journal of Food Products Marketing, 11(4), 109-117.

Han, M. C. (1989). Country Image: Halo or Summary Construct?. Journal of Marketing Research, 26(2), 222-229.

Haque, A., Anwar, N., Yasmin, F., Sarwar, A., Ibrahim, Z., \& Momen, A. (2015). Purchase Intention of Foreign Products: A Study on Bangladeshi Consumer Perspective. SAGE Open, 5(2), 1-12.

Hasiloglu, S. B. (2012). Evaluation of Turkish Origin Textile Products Image with Fuzzy Logic. Journal of Textile \& Apparel, 22(3), 169-176

Javed, A., \& Hasnu, S. A. F. (2013). Impact of Country-Of-Origin on Product Purchase Decision. Journal of Marketing and Consumer Research, 1, 31-51.

Kavak, B., Özkan, Ö. ve Demirsoy, C. (2004). Avrupa Birliği Ülkelerine Ait Ürünlerin Esas Ülke Etkilerinin Milliyet Merkezcilik Çerçevesinde Araştırılması. Hacettepe Üniversitesi İktisadi ve İdari Bilimler Fakültesi Dergisi, 22(2), 111-124.

Kaynak, E., \& Kara, A. (1998). Consumer Ethnocentrism and Lifestyle Orientations in an Emerging Market Economy. MIR: Management International Review, 38, 53-72.

Kaynak, E., \& Kara, A. (2002). Consumer Perceptions of Foreign Products: An Analysis of Product-Country Images and Ethnocentrism. European Journal of Marketing, 36(7/8), 928-949.

Lo, S. C., Tung, J., Wang, K. Y., \& Huang, K. P. (2017). Country-Of-Origin and Consumer Ethnocentrism: Effect on Brand Image and Product Evaluation. Journal of Applied Sciences, 17(7), 357-364. 
Özden K., \& Maksüdünov, A. (2012). The Importance of Country of Origin on Purchasing Durable Consumer Goods: In Case of Kyrgyzstan. Journal of Yaşar University, 7(25), 4348-4356.

Toksarı, M. ve Senir, G. (2015). Menşe Ülke Etkisinin Satın Alma Kararı Üzerindeki Etkisi. Journal of International Social Research, 8(40), 793-805. 